\title{
Diels-Alder Approach to Tetra-ortho-Substituted Biaryls Employing Propargylic Tertiary Alcohols as Dienophiles.
}

\author{
Bradley O. Ashburn and Rich G. Carter* \\ Department of Chemistry, Oregon State University, Corvallis, OR 97331.
}

Electronic Supplementary Information: Experimental 
General. Infrared spectra were recorded neat unless otherwise indicated and are reported in $\mathrm{cm}^{-1} .{ }^{1} \mathrm{H}$ NMR spectra were recorded in deuterated solvents and are reported in ppm relative to tetramethylsilane and referenced internally to the residually protonated solvent. ${ }^{13} \mathrm{C}$ NMR spectra were recorded in deuterated solvents and are reported in ppm relative to tetramethylsilane and referenced internally to the residually protonated solvent.

Routine monitoring of reactions was performed using EM Science DC-Alufolien silica gel, aluminumbacked TLC plates. Flash chromatography was performed with the indicated eluents on EM Science Gedurian 230400 mesh silica gel.

Air and/or moisture sensitive reactions were performed under usual inert atmosphere conditions. Reactions requiring anhydrous conditions were performed under a blanket of argon, in glassware dried in an oven at $120^{\circ} \mathrm{C}$ or by flame, then cooled under argon. Dry DMF, THF, DCM, and PhMe were obtained via a solvent purification system. All other solvents and commercially available reagents were either purified via literature procedures or used without further purification.

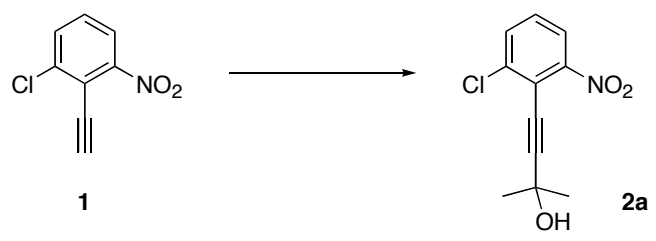

Acetylene 2a: To a stirred solution of $\mathbf{1}(46.6 \mathrm{mg}, 0.257 \mathrm{mmol})$ and THF $(1.25 \mathrm{~mL})$ was added LDA ${ }^{1}$ $\left(0.257 \mathrm{~mL}, 0.257 \mathrm{mmol}, 1.0 \mathrm{M}\right.$ in THF / Hexanes) at $-78^{\circ} \mathrm{C}$. After $5 \mathrm{~min}$, freshly distilled acetone (44.8 $\mathrm{mg}, 56.6$ $\mu \mathrm{L}, 0.771 \mathrm{mmol}$ ) was added. After $30 \mathrm{~min}$ at $-78^{\circ} \mathrm{C}$, the dark brown solution was allowed to warm to rt. After an additional $1 \mathrm{~h}$, the mixture was quenched with sat. aq. $\mathrm{NH}_{4} \mathrm{Cl}(15 \mathrm{~mL})$, diluted with EtOAc $(15 \mathrm{~mL})$, and washed with $\mathrm{H}_{2} \mathrm{O}(15 \mathrm{~mL})$ and sat. aq. $\mathrm{NaCl}(15 \mathrm{~mL})$. The dried extract $\left(\mathrm{MgSO}_{4}\right)$ was concentrated in vacuo and purified by chromatography over silica gel, eluting with $20 \%$ EtOAc / Hexanes to give 2a (43.8 mg, $0.183 \mathrm{mmol}, 71 \%)$ as a yellow oil. IR (neat) $3407,2984,2232,1532 \mathrm{~cm}^{-1} ;{ }^{1} \mathrm{H} \mathrm{NMR}\left(300 \mathrm{MHz}, \mathrm{CDCl}_{3}\right) \delta 7.89(\mathrm{dd}, J=8.3,1.1 \mathrm{~Hz}, 1 \mathrm{H})$, $7.69(\mathrm{dd}, J=8.2,1.2 \mathrm{~Hz}, 1 \mathrm{H}), 7.39(\mathrm{t}, J=8.2 \mathrm{~Hz}, 1 \mathrm{H}), 2.27(\mathrm{~s}, 1 \mathrm{H}), 1.68(\mathrm{~s}, 3 \mathrm{H}) ;{ }^{13} \mathrm{C} \mathrm{NMR}\left(75 \mathrm{MHz}, \mathrm{CDCl}_{3}\right) \delta$ $151.4,138.7,133.5,128.5,122.7,117.9,107.9,74.4,65.9,30.9$; HRMS (CI+) calcd. for $\mathrm{C}_{11} \mathrm{H}_{10} \mathrm{NO}_{3} \mathrm{ClNa}(\mathrm{M}+\mathrm{Na})$ 262.0247, found 262.0241.

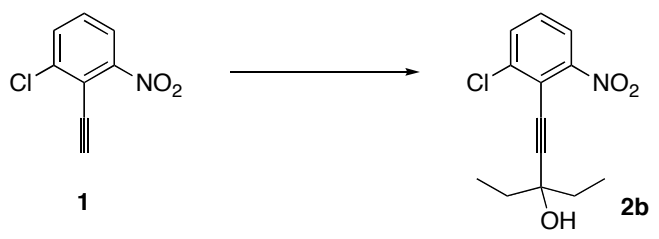

Acetylene 2b: To a stirred solution of $1(106 \mathrm{mg}, 0.584 \mathrm{mmol})$ and THF $(2.92 \mathrm{~mL})$ was added LDA ${ }^{1}$ $\left(0.584 \mathrm{~mL}, 0.584 \mathrm{mmol}, 1.0 \mathrm{M}\right.$ in THF / Hexanes) at $-78^{\circ} \mathrm{C}$. After $5 \mathrm{~min}, 3$-pentanone $(151 \mathrm{mg}, 185 \mu \mathrm{L}, 1.75$ mmol) was added. After $30 \mathrm{~min}$ at $-78^{\circ} \mathrm{C}$, the dark brown solution was allowed to warm to rt. After an additional 1 h, the mixture was quenched with sat. aq. $\mathrm{NH}_{4} \mathrm{Cl}(15 \mathrm{~mL})$, diluted with EtOAc $(15 \mathrm{~mL})$, and washed with $\mathrm{H}_{2} \mathrm{O}(15$ $\mathrm{mL})$ and sat. aq. $\mathrm{NaCl}(15 \mathrm{~mL})$. The dried extract $\left(\mathrm{MgSO}_{4}\right)$ was concentrated in vacuo and purified by chromatography over silica gel, eluting with $20 \%$ EtOAc / Hexanes to give $\mathbf{2 b}(98.5 \mathrm{mg}, 0.368 \mathrm{mmol}, 63 \%)$ as a yellow oil. IR (neat) $3443,2972,2229,1533 \mathrm{~cm}^{-1} ;{ }^{1} \mathrm{H} \mathrm{NMR}\left(300 \mathrm{MHz}, \mathrm{CDCl}_{3}\right) \delta 7.89$ (dd, $\left.J=8.2,1.2 \mathrm{~Hz}, 1 \mathrm{H}\right)$, $7.69(\mathrm{dd}, J=8.1,1.1 \mathrm{~Hz}, 1 \mathrm{H}), 7.39(\mathrm{t}, J=8.2 \mathrm{~Hz}, 1 \mathrm{H}), 2.24(\mathrm{bs}, 1 \mathrm{H}), 1.76-1.90(\mathrm{~m}, 4 \mathrm{H}), 1.14(\mathrm{t}, J=7.2 \mathrm{~Hz}, 6 \mathrm{H})$; ${ }^{13} \mathrm{C}$ NMR $\left(75 \mathrm{MHz}, \mathrm{CDCl}_{3}\right) \delta 151.5,138.8,133.5,128.5,122.6,118.0,106.4,76.6,73.0,34.2,8.52$; HRMS (EI+) calcd. for $\mathrm{C}_{13} \mathrm{H}_{14} \mathrm{NO}_{3} \mathrm{Cl}(\mathrm{M}+\mathrm{H}) 267.0662$, found 267.0659. 


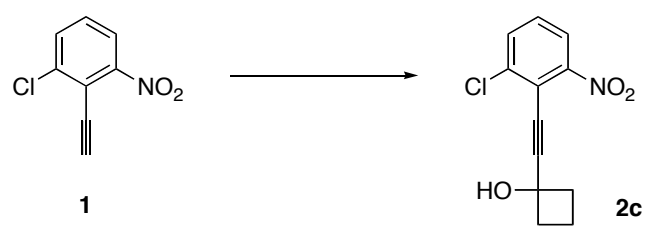

Acetylene 2c: To a stirred solution of $1(108 \mathrm{mg}, 0.594 \mathrm{mmol})$ and THF $(2.97 \mathrm{~mL})$ was added LDA ${ }^{1}$ $\left(0.594 \mathrm{~mL}, 0.594 \mathrm{mmol}, 1.0 \mathrm{M}\right.$ in THF / Hexanes) at $-78^{\circ} \mathrm{C}$. After $5 \mathrm{~min}$, cyclobutanone $(125 \mathrm{mg}, 150 \mu \mathrm{L}, 1.78$ mmol) was added. After $30 \mathrm{~min}$ at $-78^{\circ} \mathrm{C}$, the dark brown solution was allowed to warm to rt. After an additional 1 $\mathrm{h}$, the mixture was quenched with sat. aq. $\mathrm{NH}_{4} \mathrm{Cl}(15 \mathrm{~mL})$, diluted with EtOAc $(15 \mathrm{~mL})$, and washed with $\mathrm{H}_{2} \mathrm{O}(15$ $\mathrm{mL})$ and sat. aq. $\mathrm{NaCl}(15 \mathrm{~mL})$. The dried extract $\left(\mathrm{MgSO}_{4}\right)$ was concentrated in vacuo and purified by chromatography over silica gel, eluting with $10 \%$ EtOAc / Hexanes to give $2 \mathbf{c}(90.4 \mathrm{mg}, 0.359 \mathrm{mmol}, 60 \%)$ as a yellow oil. IR (neat) 3374, 2992, 2228, $1531 \mathrm{~cm}^{-1} ;{ }^{1} \mathrm{H} \mathrm{NMR}\left(400 \mathrm{MHz}, \mathrm{CDCl}_{3}\right) \delta 7.92$ (dd, $J=8.2,1.1 \mathrm{~Hz}, 1 \mathrm{H}$ ), $7.71(\mathrm{dd}, J=8.0,1.1 \mathrm{~Hz}, 1 \mathrm{H}), 7.41(\mathrm{t}, J=8.2 \mathrm{~Hz}, 1 \mathrm{H}), 2.64(\mathrm{bs}, 1 \mathrm{H}), 2.57-2.65(\mathrm{~m}, 2 \mathrm{H}), 2.38-2.46(\mathrm{~m}, 2 \mathrm{H}), 1.87-$ $2.01(\mathrm{~m}, 2 \mathrm{H}) ;{ }^{13} \mathrm{C} \mathrm{NMR}\left(100 \mathrm{MHz}, \mathrm{CDCl}_{3}\right) \delta 151.2,138.6,133.6,128.5,122.8,118.0,107.0,75.7,68.4,38.4,12.9$; HRMS (EI+) calcd. for $\mathrm{C}_{12} \mathrm{H}_{10} \mathrm{NO}_{3} \mathrm{Cl}(\mathrm{M}+\mathrm{H}) 251.0349$, found 251.0347 .

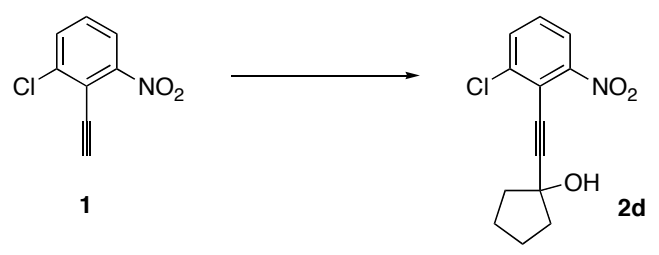

Acetylene 2d: To a stirred solution of $\mathbf{1}(92.6 \mathrm{mg}, 0.510 \mathrm{mmol})$ and THF $(2.55 \mathrm{~mL})$ was added LDA ${ }^{1}$ $\left(0.510 \mathrm{~mL}, 0.510 \mathrm{mmol}, 1.0 \mathrm{M}\right.$ in THF / Hexanes) at $-78^{\circ} \mathrm{C}$. After $5 \mathrm{~min}$, cyclopentanone $(129 \mathrm{mg}, 135 \mu \mathrm{L}, 1.53$ mmol) was added. After $30 \mathrm{~min}$ at $-78^{\circ} \mathrm{C}$, the dark brown solution was allowed to warm to rt. After an additional 1 $\mathrm{h}$, the mixture was quenched with sat. aq. $\mathrm{NH}_{4} \mathrm{Cl}(15 \mathrm{~mL})$, diluted with EtOAc $(15 \mathrm{~mL})$, and washed with $\mathrm{H}_{2} \mathrm{O}(15$ $\mathrm{mL})$ and sat. aq. $\mathrm{NaCl}(15 \mathrm{~mL})$. The dried extract $\left(\mathrm{MgSO}_{4}\right)$ was concentrated in vacuo and purified by chromatography over silica gel, eluting with 10\% EtOAc / Hexanes to give 2d (70.4 mg, $0.265 \mathrm{mmol}, 52 \%)$ as a yellow oil. IR (neat) $3410,2959,2216,1531 \mathrm{~cm}^{-1} ;{ }^{1} \mathrm{H}$ NMR $\left(300 \mathrm{MHz}, \mathrm{CDCl}_{3}\right) \delta 7.90$ (dd, $J=8.3,1.2 \mathrm{~Hz}, 1 \mathrm{H}$ ), $7.69(\mathrm{dd}, J=8.1,1.1 \mathrm{~Hz}, 1 \mathrm{H}), 7.38(\mathrm{t}, J=8.2 \mathrm{~Hz}, 1 \mathrm{H}), 2.03-2.19(\mathrm{~m}, 5 \mathrm{H}), 1.81-1.96(\mathrm{~m}, 4 \mathrm{H}) ;{ }^{13} \mathrm{C}$ NMR $(75 \mathrm{MHz}$, $\left.\mathrm{CDCl}_{3}\right) \delta 151.3,138.6,133.5,128.4,122.7,118.1,107.5,75.4,75.1,42.3,23.6$; HRMS (EI+) calcd. for $\mathrm{C}_{13} \mathrm{H}_{12} \mathrm{NO}_{3} \mathrm{Cl}(\mathrm{M}+\mathrm{H})$ 265.0506, found 265.0509.

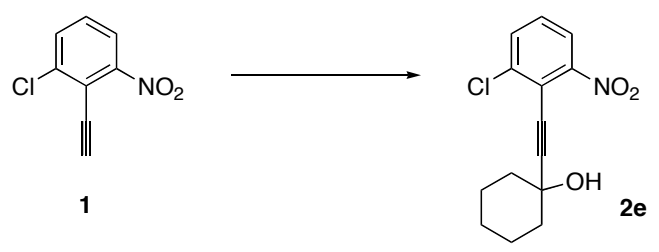

Acetylene 2e: To a stirred solution of $\mathbf{1}(89.3 \mathrm{mg}, 0.492 \mathrm{mmol})$ and THF $(2.46 \mathrm{~mL})$ was added LDA ${ }^{1}$ $\left(0.492 \mathrm{~mL}, 0.492 \mathrm{mmol}, 1.0 \mathrm{M}\right.$ in THF / Hexanes) at $-78^{\circ} \mathrm{C}$. After $5 \mathrm{~min}$, the dark brown solution was cannulated into a stirred solution of cyclohexanone $(144 \mathrm{mg}, 153 \mu \mathrm{L}, 1.48 \mathrm{mmol})$ in THF $(0.49 \mathrm{~mL})$ at $-78^{\circ} \mathrm{C}$. After $30 \mathrm{~min}$ at $-78^{\circ} \mathrm{C}$, the solution was allowed to warm to rt. After an additional $1 \mathrm{~h}$, the mixture was quenched with sat. aq. $\mathrm{NH}_{4} \mathrm{Cl}(15 \mathrm{~mL})$, diluted with EtOAc $(15 \mathrm{~mL})$, and washed with $\mathrm{H}_{2} \mathrm{O}(15 \mathrm{~mL})$ and sat. aq. $\mathrm{NaCl}(15 \mathrm{~mL})$. The dried extract $\left(\mathrm{MgSO}_{4}\right)$ was concentrated in vacuo and purified by chromatography over silica gel, eluting with $20 \%$ EtOAc / Hexanes to give 2e (93.2 mg, $0.333 \mathrm{mmol}, 68 \%)$ as a yellow oil. IR (neat) 3398, 2936, 2232, $1532 \mathrm{~cm}^{-1} ;{ }^{1} \mathrm{H}$ $\operatorname{NMR}\left(300 \mathrm{MHz}, \mathrm{CDCl}_{3}\right) \delta 7.89(\mathrm{dd}, J=8.3,1.2 \mathrm{~Hz}, 1 \mathrm{H}), 7.69(\mathrm{dd}, J=8.1,1.2 \mathrm{~Hz}, 1 \mathrm{H}), 7.39(\mathrm{t}, J=8.2 \mathrm{~Hz}, 1 \mathrm{H})$, $2.41(\mathrm{~s}, 1 \mathrm{H}), 2.08-2.12(\mathrm{~m}, 2 \mathrm{H}), 1.61-1.82(\mathrm{~m}, 8 \mathrm{H}), 1.26-1.30(\mathrm{~m}, 1 \mathrm{H}) ;{ }^{13} \mathrm{C} \mathrm{NMR}\left(75 \mathrm{MHz}, \mathrm{CDCl}_{3}\right) \delta 151.3,138.7$, 
133.5, 128.4, 122.7, 118.1, 107.4, 76.3, 69.6, 39.6, 25.1, 23.2; HRMS (EI+) calcd. for $\mathrm{C}_{14} \mathrm{H}_{14} \mathrm{NO}_{3} \mathrm{Cl}(\mathrm{M}+\mathrm{H})$ 279.0662 , found 279.0625 .

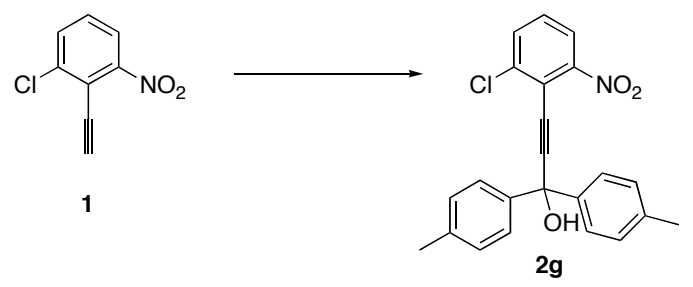

Acetylene 2g: To a stirred solution of $1(57.2 \mathrm{mg}, 0.315 \mathrm{mmol})$ and THF $(1.58 \mathrm{~mL})$ was added LDA ${ }^{1}$ $\left(0.315 \mathrm{~mL}, 0.315 \mathrm{mmol}, 1.0 \mathrm{M}\right.$ in THF / Hexanes) at $-78^{\circ} \mathrm{C}$. After $5 \mathrm{~min}, 4,4^{\prime}$-dimethylbenzophenone (199 $\mathrm{mg}$, $0.945 \mathrm{mmol}$ ) was added. After $30 \mathrm{~min}$ at $-78^{\circ} \mathrm{C}$, the dark brown solution was allowed to warm to rt. After an additional $1 \mathrm{~h}$, the mixture was quenched with sat. aq. $\mathrm{NH}_{4} \mathrm{Cl}(15 \mathrm{~mL})$, diluted with EtOAc $(15 \mathrm{~mL})$, and washed with $\mathrm{H}_{2} \mathrm{O}(15 \mathrm{~mL})$ and sat. aq. $\mathrm{NaCl}(15 \mathrm{~mL})$. The dried extract $\left(\mathrm{MgSO}_{4}\right)$ was concentrated in vacuo and purified by chromatography over silica gel, eluting with $20 \%$ EtOAc / Hexanes to give $\mathbf{2 g}(95.7 \mathrm{mg}, 0.244 \mathrm{mmol}, 78 \%)$ as a yellow oil. IR (neat) 3528, 2919, 2216, $1531 \mathrm{~cm}^{-1} ;{ }^{1} \mathrm{H}$ NMR (300 MHz, $\left.\mathrm{CDCl}_{3}\right) \delta 7.97$ (dd, $J=8.3,1.2 \mathrm{~Hz}, 1 \mathrm{H}$ ), $7.72(\mathrm{dd}, J=8.1,1.2 \mathrm{~Hz}, 1 \mathrm{H}), 7.58-7.62(\mathrm{~m}, 4 \mathrm{H}), 7.41(\mathrm{t}, J=8.2 \mathrm{~Hz}, 1 \mathrm{H}), 7.17-7.28(\mathrm{~m}, 4 \mathrm{H}), 2.92(\mathrm{~s}, 1 \mathrm{H}), 2.36(\mathrm{~s}$, $6 \mathrm{H}) ;{ }^{13} \mathrm{C}$ NMR $\left(75 \mathrm{MHz}, \mathrm{CDCl}_{3}\right) \delta 151.0,141.4,139.0,137.7,133.7,129.1,128.7,126.1,122.9,117.9,106.1,78.9$, 75.0, 21.1; HRMS (ES+) calcd. for $\mathrm{C}_{23} \mathrm{H}_{18} \mathrm{NO}_{3} \mathrm{NaCl}(\mathrm{M}+\mathrm{Na})$ 414.0873, found 414.0869.

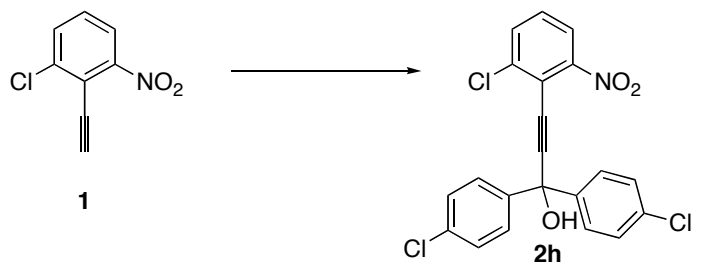

Acetylene 2h: To a stirred solution of $\mathbf{1}(54.0 \mathrm{mg}, 0.297 \mathrm{mmol})$ and THF $(1.49 \mathrm{~mL})$ was added LDA ${ }^{1}$ $\left(0.297 \mathrm{~mL}, 0.297 \mathrm{mmol}, 1.0 \mathrm{M}\right.$ in THF / Hexanes) at $-78^{\circ} \mathrm{C}$. After $5 \mathrm{~min}, 4,4^{\prime}$-dichlorobenzophenone (224 $\mathrm{mg}$, $0.892 \mathrm{mmol}$ ) was added. After $30 \mathrm{~min}$ at $-78^{\circ} \mathrm{C}$, the dark brown solution was allowed to warm to rt. After an additional $1 \mathrm{~h}$, the mixture was quenched with sat. aq. $\mathrm{NH}_{4} \mathrm{Cl}(15 \mathrm{~mL})$, diluted with EtOAc $(15 \mathrm{~mL})$, and washed with $\mathrm{H}_{2} \mathrm{O}(15 \mathrm{~mL})$ and sat. aq. $\mathrm{NaCl}(15 \mathrm{~mL})$. The dried extract $\left(\mathrm{MgSO}_{4}\right)$ was concentrated in vacuo and purified by chromatography over silica gel, eluting with $20 \%$ EtOAc / Hexanes to give $\mathbf{2 h}(88.0 \mathrm{mg}, 0.203 \mathrm{mmol}, 69 \%)$ as a yellow oil. IR (neat) 3544, 2322, 1531, $1488 \mathrm{~cm}^{-1} ;{ }^{1} \mathrm{H} \mathrm{NMR}\left(400 \mathrm{MHz}, \mathrm{CDCl}_{3}\right) \delta 7.99$ (dd, $J=8.2,1.0 \mathrm{~Hz}, 1 \mathrm{H}$ ), $7.75(\mathrm{dd}, J=8.1,1.1 \mathrm{~Hz}, 1 \mathrm{H}), 7.62-7.66(\mathrm{~m}, 4 \mathrm{H}), 7.46(\mathrm{t}, J=8.2 \mathrm{~Hz}, 1 \mathrm{H}), 7.34-7.38(\mathrm{~m}, 4 \mathrm{H}), 3.27(\mathrm{~s}, 1 \mathrm{H}) ;{ }^{13} \mathrm{C} \mathrm{NMR}$ $\left(100 \mathrm{MHz}, \mathrm{CDCl}_{3}\right) \delta 150.9,142.3,139.1,134.2,133.9,129.2,128.7,127.6,123.1,117.4,104.3,79.8,74.4$; HRMS (ES+) calcd. for $\mathrm{C}_{21} \mathrm{H}_{12} \mathrm{NO}_{3} \mathrm{NaCl}_{3}(\mathrm{M}+\mathrm{Na})$ 453.9780, found 453.9766 .

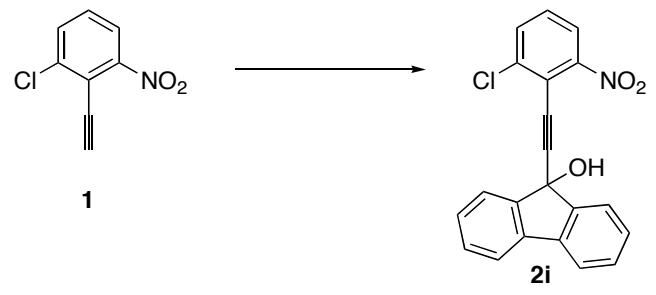

Acetylene 2i: $\quad$ To a stirred solution of $1(50.9 \mathrm{mg}, 0.280 \mathrm{mmol})$ and THF $(1.40 \mathrm{~mL})$ was added $\mathrm{LDA}^{1}$ $\left(0.280 \mathrm{~mL}, 0.280 \mathrm{mmol}, 1.0 \mathrm{M}\right.$ in THF / Hexanes) at $-78^{\circ} \mathrm{C}$. After $5 \mathrm{~min}$, 9-fluorenone (152 $\left.\mathrm{mg}, 0.841 \mathrm{mmol}\right)$ was added. After $30 \mathrm{~min}$ at $-78^{\circ} \mathrm{C}$, the dark brown solution was allowed to warm to rt. After an additional $1 \mathrm{~h}$, the 
mixture was quenched with sat. aq. $\mathrm{NH}_{4} \mathrm{Cl}(15 \mathrm{~mL})$, diluted with EtOAc $(15 \mathrm{~mL})$, and washed with $\mathrm{H}_{2} \mathrm{O}(15 \mathrm{~mL})$ and sat. aq. $\mathrm{NaCl}(15 \mathrm{~mL})$. The dried extract $\left(\mathrm{MgSO}_{4}\right)$ was concentrated in vacuo and purified by chromatography over silica gel, eluting with 20-40\% EtOAc / Hexanes to give $2 \mathbf{i}(78.2 \mathrm{mg}, 0.216 \mathrm{mmol}, 77 \%)$ as a yellow solid. Mp

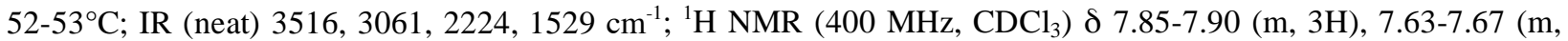
$3 \mathrm{H}), 7.39-7.47(\mathrm{~m}, 4 \mathrm{H}), 7.34(\mathrm{t}, J=8.2 \mathrm{~Hz}, 1 \mathrm{H}), 3.01(\mathrm{~s}, 1 \mathrm{H}) ;{ }^{13} \mathrm{C}$ NMR $\left(100 \mathrm{MHz}, \mathrm{CDCl}_{3}\right) \delta 151.2,146.1,139.4$, $139.3,133.7,130.0,128.9,128.7,124.8,122.8,120.4,117.7,103.0,75.3,75.0$; HRMS (ES+) calcd. for $\mathrm{C}_{21} \mathrm{H}_{12} \mathrm{NO}_{3} \mathrm{NaCl}(\mathrm{M}+\mathrm{Na}) 384.0403$, found 384.0370 .

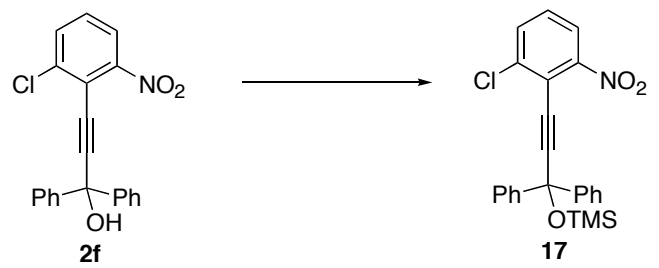

Acetylene 17: To a stirred solution of $\mathbf{2 f}(97.0 \mathrm{mg}, 0.267 \mathrm{mmol})$ in DMF $(0.27 \mathrm{~mL})$ was added imidazole $(54.5 \mathrm{mg}, 0.801 \mathrm{mmol})$ and TMSCl $(144 \mathrm{mg}, 0.170 \mathrm{~mL}, 1.33 \mathrm{mmol})$ at r.t. After $2 \mathrm{~h}$, the reaction was quenched with sat. aq. $\mathrm{NaHCO}_{3}(15 \mathrm{~mL})$, diluted with EtOAc $(15 \mathrm{~mL})$ and washed with $\mathrm{H}_{2} \mathrm{O}(2 \times 15 \mathrm{~mL})$ and sat. aq. $\mathrm{NaCl}$ $(15 \mathrm{~mL})$. The dried extract $\left(\mathrm{MgSO}_{4}\right)$ was concentrated in vacuo and purified by chromatography over silica gel, eluting with 20-50\% $\mathrm{CH}_{2} \mathrm{Cl}_{2}$ / Hexanes to give recovered $\mathbf{2 f}(28.0 \mathrm{mg}, 0.0769 \mathrm{mmol})$ and $\mathbf{1 7}(76.2 \mathrm{mg}, 0.175 \mathrm{mmol}$, $65 \% / 88 \%$ borsm) as an oil. IR (neat) $2963,2220,1534,1450 \mathrm{~cm}^{-1} ;{ }^{1} \mathrm{H}$ NMR $\left(400 \mathrm{MHz}, \mathrm{CDCl}_{3}\right) \delta 7.94(\mathrm{dd}, J=$ 8.2, 1.1 Hz, 1H), $7.72(\mathrm{dd}, J=8.1,1.1 \mathrm{~Hz}, 1 \mathrm{H}), 7.66-7.71(\mathrm{~m}, 4 \mathrm{H}), 7.44(\mathrm{t}, J=8.2 \mathrm{~Hz}, 1 \mathrm{H}), 7.34-7.38(\mathrm{~m}, 4 \mathrm{H}), 7.25-$ $7.31(\mathrm{~m}, 2 \mathrm{H}), 0.15(\mathrm{~s}, 9 \mathrm{H}) ;{ }^{13} \mathrm{C} \mathrm{NMR}\left(75 \mathrm{MHz}, \mathrm{CDCl}_{3}\right) \delta 151.4,145.7,139.3,133.6,128.8,128.0,127.5,126.5$, 122.7, 117.8, 105.8, 79.9, 76.5, 1.55; HRMS (CI+) calcd. for $\mathrm{C}_{24} \mathrm{H}_{22} \mathrm{NO}_{3} \mathrm{ClSi}(\mathrm{M}+\mathrm{H}) 435.1058$, found 435.1056 .

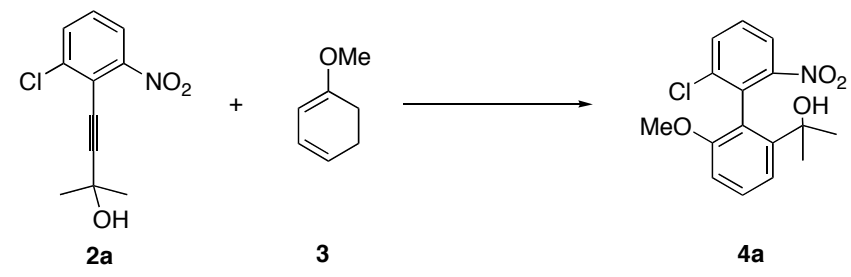

Biaryl 4a: To a pressure vessel containing $2 \mathrm{a}(32.5 \mathrm{mg}, 0.136 \mathrm{mmol})$ and xylenes $(0.27 \mathrm{~mL})$ was added diene $3(44.8 \mathrm{mg}, 48.2 \mu \mathrm{L}, 0.417 \mathrm{mmol})$ at r.t. The mixture was heated at $145^{\circ} \mathrm{C}$ for $36 \mathrm{~h}$. The crude material was purified by chromatography over silica gel, eluting with 10-30\% EtOAc / Hexanes to give 4a (35.3 mg, $0.110 \mathrm{mmol}$, $80 \%$ ) as a yellow crystalline solid. Mp $139-40^{\circ} \mathrm{C}$; IR (neat) $3561,2923,1529,1425 \mathrm{~cm}^{-1}$; ${ }^{1} \mathrm{H}$ NMR (300 MHz, $\left.\mathrm{CDCl}_{3}\right) \delta 7.85(\mathrm{dd}, J=8.2,1.2 \mathrm{~Hz}, 1 \mathrm{H}), 7.68(\mathrm{dd}, J=8.1,1.3 \mathrm{~Hz}, 1 \mathrm{H}), 7.39(\mathrm{t}, J=8.1 \mathrm{~Hz}, 1 \mathrm{H}), 7.38(\mathrm{t}, J=8.1 \mathrm{~Hz}$, $1 \mathrm{H}), 7.02(\mathrm{dd}, J=7.9,0.9 \mathrm{~Hz}, 1 \mathrm{H}), 6.87(\mathrm{dd}, J=7.8,0.8 \mathrm{~Hz}, 1 \mathrm{H}), 3.67(\mathrm{~s}, 3 \mathrm{H}), 1.67$ (s, $1 \mathrm{H}), 1.60(\mathrm{~s}, 3 \mathrm{H}), 1.49$ (s, $3 \mathrm{H}) ;{ }^{13} \mathrm{C}$ NMR $\left(75 \mathrm{MHz}, \mathrm{CDCl}_{3}\right) \delta 156.7,150.4,147.5,136.1,134.9,133.1,129.5,127.8,121.9,121.2,119.2$, 109.1, 74.3, 56.2, 32.6, 31.4; HRMS (ES+) calcd. for $\mathrm{C}_{16} \mathrm{H}_{16} \mathrm{NO}_{4} \mathrm{NaCl}(\mathrm{M}+\mathrm{Na}) 344.0666$, found 344.0681.

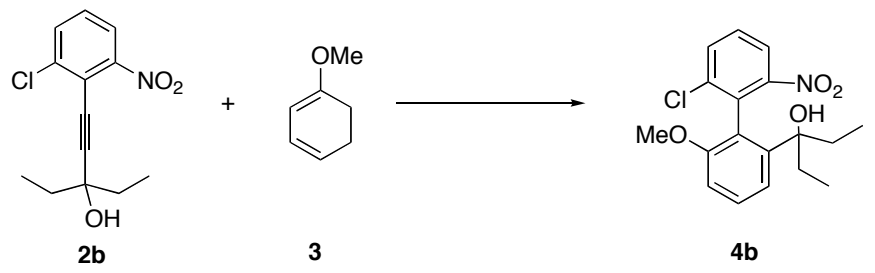

Biaryl 4b: To a pressure vessel containing $2 \mathbf{b}(80.1 \mathrm{mg}, 0.299 \mathrm{mmol})$ and xylenes $(0.60 \mathrm{~mL})$ was added diene $3(98.9 \mathrm{mg}, 106 \mu \mathrm{L}, 0.897 \mathrm{mmol})$ at r.t. The mixture was heated at $145^{\circ} \mathrm{C}$ for $36 \mathrm{~h}$. The crude material was 
purified by chromatography over silica gel, eluting with $10 \%$ EtOAc / Hexanes to give $\mathbf{4 b}(60.1 \mathrm{mg}, 0.172 \mathrm{mmol}$, $58 \%$ ) as a yellow crystalline solid. Mp 92-93 ${ }^{\circ} \mathrm{C}$; IR (neat) $3471,2976,1527,1462 \mathrm{~cm}^{-1}$; ${ }^{1} \mathrm{H}$ NMR (400 MHz, $\left.\mathrm{CDCl}_{3}\right) \delta 7.89(\mathrm{dd}, J=8.2,1.2 \mathrm{~Hz}, 1 \mathrm{H}), 7.68(\mathrm{dd}, J=8.0,1.2 \mathrm{~Hz}, 1 \mathrm{H}), 7.39(\mathrm{t}, J=8.1 \mathrm{~Hz}, 2 \mathrm{H}), 6.88-6.92(\mathrm{~m}, 2 \mathrm{H})$, $3.71(\mathrm{~s}, 3 \mathrm{H}), 1.91-2.00(\mathrm{~m}, 1 \mathrm{H}), 1.64-1.86(\mathrm{~m}, 4 \mathrm{H}), 0.82(\mathrm{t}, J=7.4 \mathrm{~Hz}, 6 \mathrm{H}) ;{ }^{13} \mathrm{C}$ NMR $\left(100 \mathrm{MHz}, \mathrm{CDCl}_{3}\right) \delta 157.4$, 150.4, 144.3, 135.9, 135.4, 133.2, 128.9, 127.6, 122.9, 122.2, 120.3, 108.9, 79.2, 56.2, 34.6, 33.6, 8.54, 7.56; HRMS (EI+) calcd. for $\mathrm{C}_{18} \mathrm{H}_{20} \mathrm{NO}_{4} \mathrm{Cl}(\mathrm{M}+\mathrm{H}) 349.1081$, found 349.1085 .

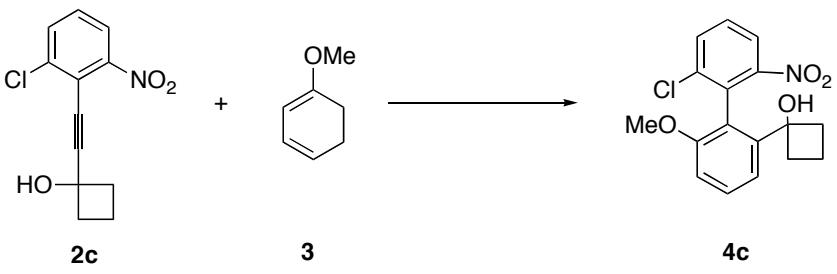

Biaryl 4c: To a pressure vessel containing $2 \mathbf{c}(76.9 \mathrm{mg}, 0.306 \mathrm{mmol})$ and xylenes $(0.61 \mathrm{~mL})$ was added diene $3(101 \mathrm{mg}, 109 \mu \mathrm{L}, 0.917 \mathrm{mmol})$ at r.t. The mixture was heated at $145^{\circ} \mathrm{C}$ for $36 \mathrm{~h}$. The crude material was purified by chromatography over silica gel, eluting with 10-20\% EtOAc / Hexanes to give 4c (68.6 mg, $0.205 \mathrm{mmol}$, $67 \%$ ) as a yellow crystalline solid. Mp $116-17^{\circ} \mathrm{C}$; IR (neat) $3420,2935,1530,1470 \mathrm{~cm}^{-1}$; ${ }^{1} \mathrm{H}$ NMR (400 MHz, $\left.\mathrm{CDCl}_{3}\right) \delta 8.05(\mathrm{dd}, J=8.3,1.2 \mathrm{~Hz}, 1 \mathrm{H}), 7.72(\mathrm{dd}, J=8.2,1.2 \mathrm{~Hz}, 1 \mathrm{H}), 7.48(\mathrm{t}, J=8.0 \mathrm{~Hz}, 1 \mathrm{H}), 7.44(\mathrm{t}, J=8.0 \mathrm{~Hz}$, $1 \mathrm{H}), 6.98-7.01(\mathrm{~m}, 2 \mathrm{H}), 3.78(\mathrm{~s}, 3 \mathrm{H}), 2.59-2.67(\mathrm{~m}, 1 \mathrm{H}), 2.23-2.30(\mathrm{~m}, 1 \mathrm{H}), 2.07-2.18(\mathrm{~m}, 1 \mathrm{H}), 1.92-1.99(\mathrm{~m}, 2 \mathrm{H})$, 1.63-1.71 (m, 1H), 1.29-1.37 (m, 1H); ${ }^{13} \mathrm{C}$ NMR (100 MHz, $\left.\mathrm{CDCl}_{3}\right) \delta 157.2,150.9,143.2,137.2,133.5,132.5$, $129.8,128.8,122.9,122.8,118.1,110.3,78.8,56.2,35.1,34.4,15.7$; HRMS (EI+) calcd. for $\mathrm{C}_{17} \mathrm{H}_{16} \mathrm{NO}_{4} \mathrm{Cl}(\mathrm{M}+\mathrm{H})$ 333.0768 , found 333.0774 .

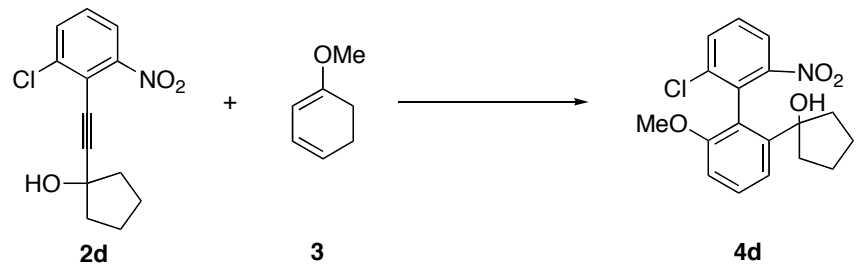

Biaryl 4d: To a pressure vessel containing $2 \mathbf{d}(48.0 \mathrm{mg}, 0.181 \mathrm{mmol})$ and xylenes $(0.36 \mathrm{~mL})$ was added diene $3(59.7 \mathrm{mg}, 64.2 \mu \mathrm{L}, 0.542 \mathrm{mmol})$ at r.t. The mixture was heated at $145^{\circ} \mathrm{C}$ for $36 \mathrm{~h}$. The crude material was purified by chromatography over silica gel, eluting with 10-30\% EtOAc / Hexanes to give 4d (34.5 mg, 0.0992 mmol, 55\%) as a yellow crystalline solid. Mp 105-06 ${ }^{\circ} \mathrm{C}$; IR (neat) $3567,2955,1528,1466 \mathrm{~cm}^{-1} ;{ }^{1} \mathrm{H}$ NMR (400 $\left.\mathrm{MHz}, \mathrm{CDCl}_{3}\right) \delta 7.97(\mathrm{dd}, J=8.2,1.2 \mathrm{~Hz}, 1 \mathrm{H}), 7.71(\mathrm{dd}, J=8.0,1.2 \mathrm{~Hz}, 1 \mathrm{H}), 7.45(\mathrm{t}, J=8.1 \mathrm{~Hz}, 1 \mathrm{H}), 7.41(\mathrm{t}, J=$ $8.1 \mathrm{~Hz}, 1 \mathrm{H}), 7.14(\mathrm{dd}, J=8.1,0.8 \mathrm{~Hz}, 1 \mathrm{H}), 6.96(\mathrm{dd}, J=8.2,0.8 \mathrm{~Hz}, 1 \mathrm{H}), 3.74(\mathrm{~s}, 3 \mathrm{H}), 2.12-2.19(\mathrm{~m}, 1 \mathrm{H}), 1.62-1.90$ $(\mathrm{m}, 7 \mathrm{H}), 1.47-1.53(\mathrm{~m}, 2 \mathrm{H}) ;{ }^{13} \mathrm{C}$ NMR $\left(100 \mathrm{MHz}, \mathrm{CDCl}_{3}\right) \delta 157.1,150.7,144.5,137.1,134.3,133.3,129.5,128.3$, 123.3, 122.4, 118.9, 109.9, 84.1, 56.2, 41.7, 38.9, 23.5, 23.1; HRMS (EI+) calcd. for $\mathrm{C}_{18} \mathrm{H}_{18} \mathrm{NO}_{4} \mathrm{Cl}(\mathrm{M}+\mathrm{H})$ 347.0924, found 347.0934.

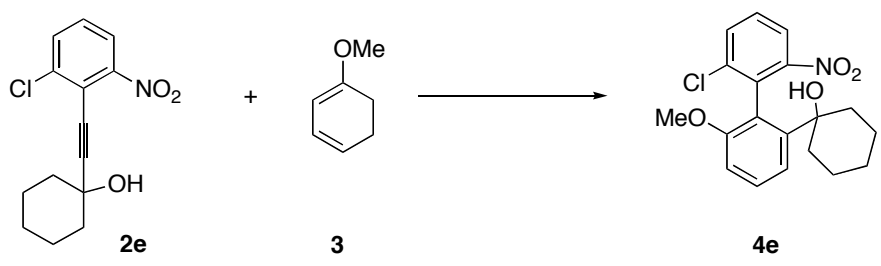

Biaryl 4e: To a pressure vessel containing $2 \mathrm{e}(77.2 \mathrm{mg}, 0.276 \mathrm{mmol})$ and xylenes $(0.55 \mathrm{~mL})$ was added diene $3(91.2 \mathrm{mg}, 98.1 \mu \mathrm{L}, 0.828 \mathrm{mmol})$ at r.t. The mixture was heated at $145^{\circ} \mathrm{C}$ for $18 \mathrm{~h}$. The crude material was 
purified by chromatography over silica gel, eluting with $10 \%$ EtOAc / Hexanes to give $4 \mathbf{e}(61.8 \mathrm{mg}, 0.171 \mathrm{mmol}$, $62 \%)$ as a yellow oil. IR (neat) $3577,2934,1526,1462 \mathrm{~cm}^{-1} ;{ }^{1} \mathrm{H}$ NMR $\left(400 \mathrm{MHz}, \mathrm{CDCl}_{3}\right) \delta 7.84$ (dd, $J=8.1,1.2$ $\mathrm{Hz}, 1 \mathrm{H}), 7.68(\mathrm{dd}, J=8.1,1.2 \mathrm{~Hz}, 1 \mathrm{H}), 7.41(\mathrm{t}, J=8.1 \mathrm{~Hz}, 1 \mathrm{H}), 7.40(\mathrm{t}, J=8.1 \mathrm{~Hz}, 1 \mathrm{H}), 7.07(\mathrm{dd}, J=8.1,0.8 \mathrm{~Hz}$, $1 \mathrm{H}), 6.86(\mathrm{dd}, J=8.2,0.8 \mathrm{~Hz}, 1 \mathrm{H}), 3.67(\mathrm{~s}, 3 \mathrm{H}), 1.95-2.02(\mathrm{~m}, 2 \mathrm{H}), 1.82-1.85(\mathrm{~m}, 1 \mathrm{H}), 1.67-1.75(\mathrm{~m}, 2 \mathrm{H}), 1.51-1.63$ (m, 4H), $1.40(\mathrm{~s}, 1 \mathrm{H}), 1.24-1.29(\mathrm{~m}, 1 \mathrm{H}) ;{ }^{13} \mathrm{C}$ NMR $\left(100 \mathrm{MHz}, \mathrm{CDCl}_{3}\right) \delta$ 156.6, 150.2, 148.4, 135.9, 135.5, 133.1, 129.4, 127.6, 121.8, 121.4, 119.3, 109.0, 75.6, 56.2, 39.2, 38.2, 25.5, 21.9, 21.8; HRMS (EI+) calcd. for $\mathrm{C}_{19} \mathrm{H}_{20} \mathrm{NO}_{4} \mathrm{Cl}(\mathrm{M}+\mathrm{H}) 361.1081$, found 361.1065.

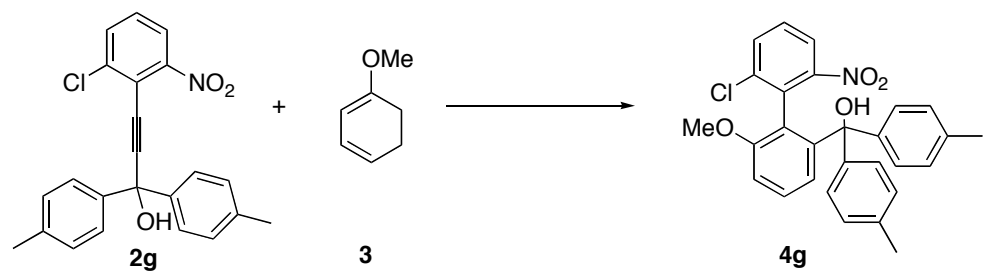

Biaryl 4g: To a pressure vessel containing $2 \mathrm{~g}(86.3 \mathrm{mg}, 0.220 \mathrm{mmol})$ and xylenes $(0.44 \mathrm{~mL})$ was added diene $3(72.8 \mathrm{mg}, 78.3 \mu \mathrm{L}, 0.661 \mathrm{mmol})$ at r.t. The mixture was heated at $145^{\circ} \mathrm{C}$ for $36 \mathrm{~h}$. The crude material was purified by chromatography over silica gel, eluting with $10 \%$ EtOAc / Hexanes to give $\mathbf{4 g}(82.2 \mathrm{mg}, 0.174 \mathrm{mmol}$, $79 \%$ ) as a yellow oil. IR (neat) 3556, 2923, 1529, $1460 \mathrm{~cm}^{-1} ;{ }^{1} \mathrm{H}$ NMR $\left(300 \mathrm{MHz}, \mathrm{CDCl}_{3}\right) \delta 7.87$ (dd, $J=8.2,1.3$ $\mathrm{Hz}, 1 \mathrm{H}), 7.43(\mathrm{dd}, J=8.2,1.3 \mathrm{~Hz}, 1 \mathrm{H}), 7.32(\mathrm{t}, J=8.0 \mathrm{~Hz}, 1 \mathrm{H}), 7.28(\mathrm{t}, J=8.1 \mathrm{~Hz}, 1 \mathrm{H}), 6.98-7.10(\mathrm{~m}, 8 \mathrm{H}), 6.96$ $(\mathrm{dd}, J=8.3,0.9 \mathrm{~Hz}, 1 \mathrm{H}), 6.63(\mathrm{dd}, J=8.0,0.9 \mathrm{~Hz}, 1 \mathrm{H}), 3.72(\mathrm{~s}, 3 \mathrm{H}), 2.52(\mathrm{~s}, 1 \mathrm{H}), 2.36(\mathrm{~s}, 3 \mathrm{H}), 2.34(\mathrm{~s}, 3 \mathrm{H}) ;{ }^{13} \mathrm{C}$ NMR $\left(75 \mathrm{MHz}, \mathrm{CDCl}_{3}\right) \delta 157.6,150.5,144.7,144.3,141.9,137.2,136.9,136.5,134.0,132.9,128.7,128.3,128.2$, $127.9,127.6,127.3,124.3,123.4,121.9,109.8,82.8,56.3,21.1$; HRMS (EI+) calcd. for $\mathrm{C}_{28} \mathrm{H}_{24} \mathrm{NO}_{4} \mathrm{Cl}(\mathrm{M}+\mathrm{H})$ 473.1394, found 473.1398 .

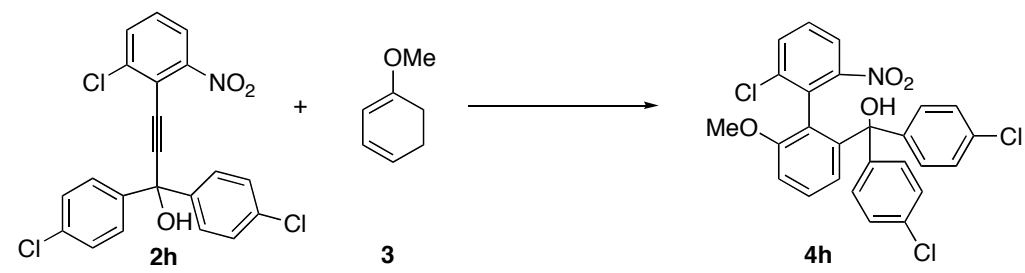

Biaryl 4h: To a pressure vessel containing $2 \mathbf{h}(63.1 \mathrm{mg}, 0.146 \mathrm{mmol})$ and xylenes $(0.29 \mathrm{~mL})$ was added diene $3(48.2 \mathrm{mg}, 51.9 \mu \mathrm{L}, 0.438 \mathrm{mmol})$ at r.t. The mixture was heated at $145^{\circ} \mathrm{C}$ for $36 \mathrm{~h}$. The crude material was purified by chromatography over silica gel, eluting with $10 \%$ EtOAc / Hexanes to give $4 \mathbf{h}$ (50.6 mg, $0.0982 \mathrm{mmol}$, $67 \%$ ) as a yellow oil. IR (neat) $3565,2947,1528,1488 \mathrm{~cm}^{-1} ;{ }^{1} \mathrm{H}$ NMR (400 MHz, $\left.\mathrm{CDCl}_{3}\right) \delta 7.88$ (dd, $J=8.1,1.2$ $\mathrm{Hz}, 1 \mathrm{H}), 7.45(\mathrm{dd}, J=8.0,1.2 \mathrm{~Hz}, 1 \mathrm{H}), 7.19-7.37(\mathrm{~m}, 6 \mathrm{H}), 7.06-7.10(\mathrm{~m}, 4 \mathrm{H}), 6.99(\mathrm{dd}, J=8.1,0.7 \mathrm{~Hz}, 1 \mathrm{H}), 6.59$ (dd, $J=8.0,0.8 \mathrm{~Hz}, 1 \mathrm{H}), 3.72(\mathrm{~s}, 3 \mathrm{H}), 2.78(\mathrm{~s}, 1 \mathrm{H}) ;{ }^{13} \mathrm{C}$ NMR $\left(100 \mathrm{MHz}, \mathrm{CDCl}_{3}\right) \delta 157.6,150.5,145.3,143.7$, $142.4,136.7,133.8,133.4,133.2,133.1,129.3,128.7,128.6,128.3,128.0,127.9,124.2,123.0,122.1,110.4,82.3$, 56.3; HRMS (EI+) calcd. for $\mathrm{C}_{26} \mathrm{H}_{18} \mathrm{NO}_{4} \mathrm{Cl}_{3}(\mathrm{M}+\mathrm{H})$ 513.0302, found 513.0323.

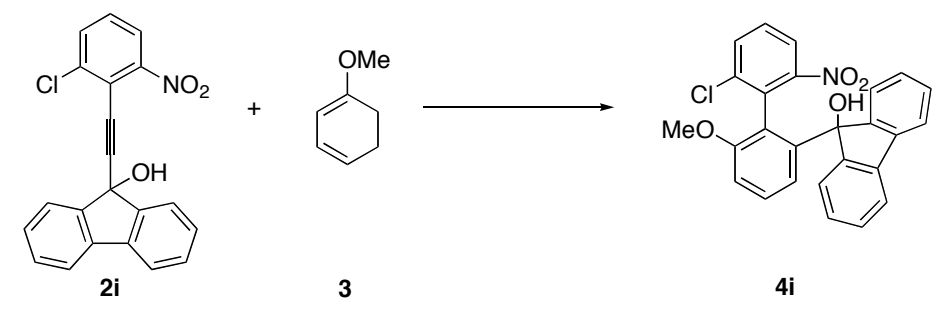

Biaryl 4i: To a pressure vessel containing $2 \mathbf{i}(72.6 \mathrm{mg}, 0.201 \mathrm{mmol})$ and xylenes $(0.40 \mathrm{~mL})$ was added 
diene $3(66.3 \mathrm{mg}, 71.4 \mu \mathrm{L}, 0.603 \mathrm{mmol})$ at r.t. The mixture was heated at $145^{\circ} \mathrm{C}$ for $36 \mathrm{~h}$. The crude material was purified by chromatography over silica gel, eluting with 10\% EtOAc / Hexanes to give 4i (61.0 mg, $0.137 \mathrm{mmol}$, $68 \%$ ) as a yellow crystalline solid. Mp 173-74 ${ }^{\circ} \mathrm{C}$; IR (neat) 3532, 2939, 1525, $1465 \mathrm{~cm}^{-1}$; ${ }^{1} \mathrm{H} \mathrm{NMR}(400 \mathrm{MHz}$, $\left.\mathrm{CDCl}_{3}\right) \delta 7.72(\mathrm{dd}, J=8.3,0.9 \mathrm{~Hz}, 1 \mathrm{H}), 7.70(\mathrm{bs}, 1 \mathrm{H}), 7.51(\mathrm{t}, J=8.1 \mathrm{~Hz}, 1 \mathrm{H}), 7.33-7.37(\mathrm{~m}, 2 \mathrm{H}), 7.26-7.31(\mathrm{~m}$, 2H), 7.19-7.24 (m, 5H), $7.09(\mathrm{t}, J=8.2 \mathrm{~Hz}, 1 \mathrm{H}), 6.99(\mathrm{~d}, J=8.3 \mathrm{~Hz}, 1 \mathrm{H}), 3.67(\mathrm{~s}, 3 \mathrm{H}), 2.17(\mathrm{~s}, 1 \mathrm{H}) ;{ }^{13} \mathrm{C} \mathrm{NMR}(100$ $\mathrm{MHz}_{\mathrm{CDCl}} \mathrm{CD}_{\mathrm{S}} \mathrm{157.1}, 149.3,149.1,148.6,139.4,139.2,139.0,137.2,133.3,132.8,129.3,129.28,128.9,128.86$, $128.3,127.8,125.3,124.9,123.0,122.7,120.1,120.01,119.5,109.9,83.3,56.1$; HRMS (EI+) calcd. for $\mathrm{C}_{26} \mathrm{H}_{18} \mathrm{NO}_{4} \mathrm{Cl}(\mathrm{M}+\mathrm{H})$ 443.0924, found 443.0940.

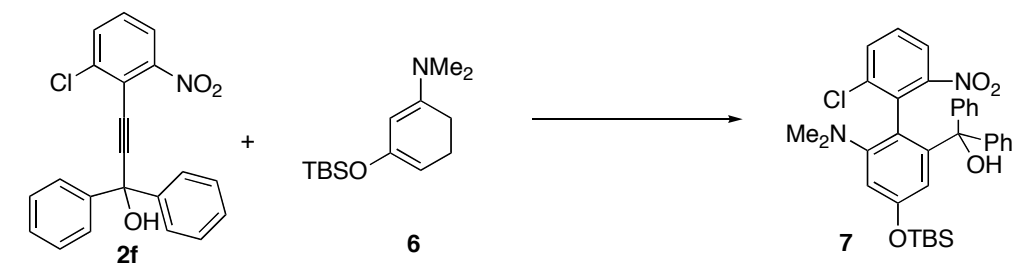

Biaryl 7: To a pressure vessel containing $2 \mathbf{f}(31.8 \mathrm{mg}, 0.0874 \mathrm{mmol})$ and xylenes $(0.18 \mathrm{~mL})$ was added crude diene $\mathbf{6}^{2}(221 \mathrm{mg}, 0.874 \mathrm{mmol})$ at r.t. The mixture was heated at $145^{\circ} \mathrm{C}$ for $24 \mathrm{~h}$ and purified by chromatography over silica gel, eluting with 10\% EtOAc / Hexanes to give 7 (22.0 mg, 0.0463 mmol, 53\%) as a bright yellow oil. IR (neat) 3566, 2919, 1594, 1528, $1352 \mathrm{~cm}^{-1} ;{ }^{1} \mathrm{H} \mathrm{NMR}\left(400 \mathrm{MHz}, \mathrm{CDCl}_{3}\right) \delta 7.91(\mathrm{dd}, J=8.0,1.6$ $\mathrm{Hz}, 1 \mathrm{H}), 7.39(\mathrm{dd}, J=7.9,1.1 \mathrm{~Hz}, 1 \mathrm{H}), 7.15-7.31(\mathrm{~m}, 11 \mathrm{H}), 6.73(\mathrm{~d}, J=2.1 \mathrm{~Hz}, 1 \mathrm{H}), 6.22(\mathrm{~d}, J=1.8 \mathrm{~Hz}, 1 \mathrm{H}), 2.80$ $(\mathrm{s}, 1 \mathrm{H}), 2.39(\mathrm{~s}, 6 \mathrm{H}), 0.93(\mathrm{~s}, 9 \mathrm{H}), 0.059(\mathrm{~s}, 3 \mathrm{H}), 0.057(\mathrm{~s}, 3 \mathrm{H}) ;{ }^{13} \mathrm{C} \mathrm{NMR}\left(100 \mathrm{MHz}, \mathrm{CDCl}_{3}\right) \delta 155.1,154.5,151.1$, $148.2,145.2,143.8,137.6,135.9,133.3,130.1,128.6,128.3,128.0,127.9,127.5,126.9,125.1,122.0,112.2,112.7$, 83.2, 44.8, 25.7, 18.1, -4.4, -4.5; HRMS (ES+) calcd. for $\mathrm{C}_{33} \mathrm{H}_{38} \mathrm{~N}_{2} \mathrm{O}_{4} \mathrm{SiCl}(\mathrm{M}+\mathrm{H})$ 589.2289, found 589.2297.

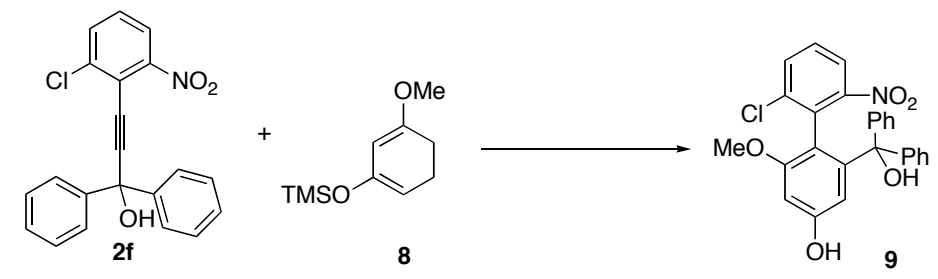

Biaryl 9: To a pressure vessel containing $2 \mathbf{f}(34.1 \mathrm{mg}, 0.0937 \mathrm{mmol})$ and xylenes $(0.19 \mathrm{~mL})$ was added diene 8 (74.4 mg, $0.375 \mathrm{mmol})$ at r.t. The mixture was heated at $145^{\circ} \mathrm{C}$ for $24 \mathrm{~h}$. To the mixture was added $\mathrm{MeOH}$ $(0.47 \mathrm{~mL})$ and $\mathrm{K}_{2} \mathrm{CO}_{3}(54.8 \mathrm{mg}, 0.937 \mathrm{mmol})$. After $30 \mathrm{~min}$, the dark brown solution was quenched with sat. aq. $\mathrm{NH}_{4} \mathrm{Cl}(15 \mathrm{~mL})$, diluted with EtOAc $(15 \mathrm{~mL})$ and washed with $\mathrm{H}_{2} \mathrm{O}(15 \mathrm{~mL})$ and sat. aq. $\mathrm{NaCl}(15 \mathrm{~mL})$. The dried extract $\left(\mathrm{MgSO}_{4}\right)$ was purified by chromatography over silica gel, eluting with 15-25\% EtOAc / Hexanes to give 9 (40.9 mg, $0.0885 \mathrm{mmol}, 95 \%$ ) as a bright yellow oil. IR (neat) 3468, 3061, 2943, 1599, $1526 \mathrm{~cm}^{-1} ;{ }^{1} \mathrm{H} \mathrm{NMR}(300$ $\left.\mathrm{MHz} \mathrm{CDCl}_{3}\right) \delta 7.83(\mathrm{dd}, J=8.0,1.3 \mathrm{~Hz}, 1 \mathrm{H}), 7.40(\mathrm{dd}, J=8.0,1.3 \mathrm{~Hz}, 1 \mathrm{H}), 7.20-7.31(\mathrm{~m}, 7 \mathrm{H}), 7.10-7.16(\mathrm{~m}, 4 \mathrm{H})$, $6.49(\mathrm{~d}, J=2.3 \mathrm{~Hz}, 1 \mathrm{H}), 6.04(\mathrm{~d}, J=2.3 \mathrm{~Hz}, 1 \mathrm{H}), 4.78(\mathrm{~s}, 1 \mathrm{H}), 3.69(\mathrm{~s}, 3 \mathrm{H}), 2.68(\mathrm{~s}, 1 \mathrm{H}) ;{ }^{13} \mathrm{C} \mathrm{NMR}(75 \mathrm{MHz}$, $\left.\mathrm{CDCl}_{3}\right) \delta 158.9,155.6,151.0,146.7,145.5,144.1,137.6,133.5,132.9,128.1,127.9,127.7,127.67,127.65,127.4$, 127.1, 121.9, 116.8, 110.3, 98.4, 82.9, 56.3; HRMS (EI+) calcd. for $\mathrm{C}_{26} \mathrm{H}_{20} \mathrm{NO}_{5} \mathrm{Cl}(\mathrm{M}+\mathrm{H})$ 461.1030, found 461.1042 . 


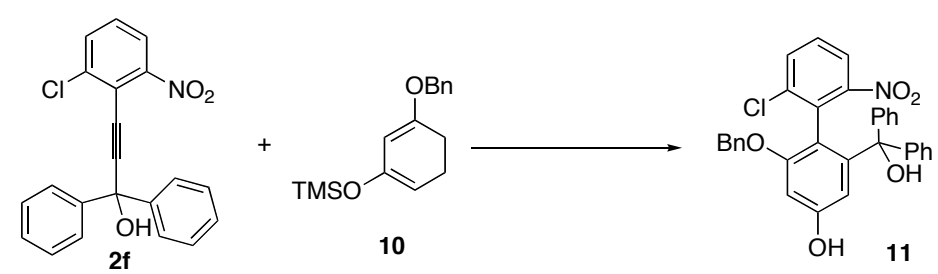

Biaryl 11: To a pressure vessel containing $\mathbf{2 f}(33.7 \mathrm{mg}, 0.0926 \mathrm{mmol})$ and xylenes $(0.19 \mathrm{~mL})$ was added diene 10 (102 mg, $0.371 \mathrm{mmol})$ at r.t. The mixture was heated at $145^{\circ} \mathrm{C}$ for $24 \mathrm{~h}$. To the mixture was added $\mathrm{MeOH}$ $(0.46 \mathrm{~mL})$ and $\mathrm{K}_{2} \mathrm{CO}_{3}(102 \mathrm{mg}, 0.926 \mathrm{mmol})$. After $30 \mathrm{~min}$, the dark brown solution was quenched with sat. aq. $\mathrm{NH}_{4} \mathrm{Cl}(15 \mathrm{~mL})$, diluted with EtOAc $(15 \mathrm{~mL})$ and washed with $\mathrm{H}_{2} \mathrm{O}(15 \mathrm{~mL})$ and sat. aq. $\mathrm{NaCl}(15 \mathrm{~mL})$. The dried extract $\left(\mathrm{MgSO}_{4}\right)$ was purified by chromatography over silica gel, eluting with $30 \%$ EtOAc / Hexanes to give 11 (36.0 mg, $0.0669 \mathrm{mmol}, 72 \%$ ) as a bright yellow oil. IR (neat) 3569, 2923, 2318, 1594, $1525 \mathrm{~cm}^{-1} ;{ }^{1} \mathrm{H} \mathrm{NMR}(300$ $\left.\mathrm{MHz} \mathrm{CDCl}_{3}\right) \delta 7.85(\mathrm{dd}, J=8.1,1.3 \mathrm{~Hz}, 1 \mathrm{H}), 7.43(\mathrm{dd}, J=8.0,1.3 \mathrm{~Hz}, 1 \mathrm{H}), 7.22-7.32(\mathrm{~m}, 10 \mathrm{H}), 7.15-7.19(\mathrm{~m}$, $4 \mathrm{H}), 7.07-7.10(\mathrm{~m}, 2 \mathrm{H}), 6.51(\mathrm{~d}, J=2.3 \mathrm{~Hz}, 1 \mathrm{H}), 6.08(\mathrm{~d}, J=2.3 \mathrm{~Hz}, 1 \mathrm{H}), 5.00(\mathrm{~s}, 2 \mathrm{H}), 4.77$ (s, $1 \mathrm{H}), 2.75(\mathrm{~s}, 1 \mathrm{H})$; ${ }^{13} \mathrm{C} \mathrm{NMR}\left(75 \mathrm{MHz}, \mathrm{CDCl}_{3}\right) \delta 157.9,155.4,150.9,146.7,145.6,144.1,137.6,136.9,133.7,132.9,128.3,128.1$, $127.9,127.72$, 127.70, 127.68, 127.5, 127.4, 127.1, 126.2, 121.9, 117.1, 110.5, 99.7, 82.9, 70.4; HRMS (EI+) calcd. for $\mathrm{C}_{32} \mathrm{H}_{24} \mathrm{NO}_{5} \mathrm{Cl}(\mathrm{M}+\mathrm{H}) 461.1030$, found 461.1022 .

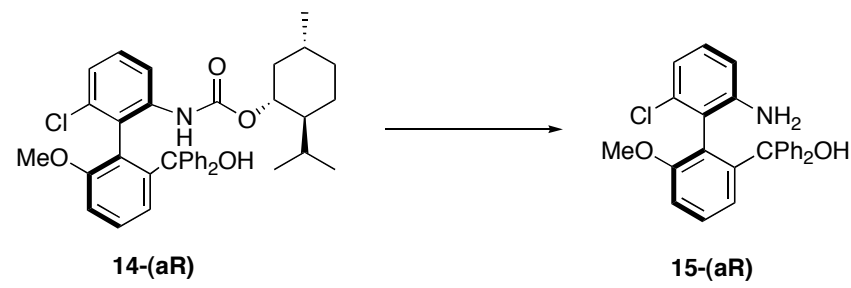

Anilino alcohol 15-(aR): To a pressure vessel was added 14-(aR) (878 mg, $1.47 \mathrm{mmol}), \mathrm{KOH}(825 \mathrm{mg}$, $14.7 \mathrm{mmol}), n$-BuOH $(2.94 \mathrm{~mL})$ and triethyleneglycol $(2.0 \mathrm{~mL})$. The solution was heated at $115^{\circ} \mathrm{C}$ for $5 \mathrm{~h}$, then quenched with $1 \mathrm{M} \mathrm{HCl}(30 \mathrm{~mL})$, diluted with EtOAc $(30 \mathrm{~mL})$ and washed with $\mathrm{H}_{2} \mathrm{O}(30 \mathrm{~mL})$, and sat. aq. $\mathrm{NaCl}(30$ $\mathrm{mL})$. The dried extract $\left(\mathrm{MgSO}_{4}\right)$ was purified by silica gel chromatography, eluting with $20 \%$ EtOAc / Hexanes to yield 15-(aR) (479 mg, $1.15 \mathrm{mmol}, 79 \%)$ as a white crystalline solid. Mp $110-11^{\circ} \mathrm{C} ;[\mathrm{a}]_{\mathrm{D}}{ }^{23}=-78.1^{\circ}(\mathrm{c}=1.34$, $\mathrm{CHCl}_{3}$ ); IR (neat) 3528, 3333, 2825, 1623, $1572 \mathrm{~cm}^{-1} ;{ }^{1} \mathrm{H} \mathrm{NMR}\left(300 \mathrm{MHz}, \mathrm{CDCl}_{3}\right) \delta 7.16-7.31(\mathrm{~m}, 11 \mathrm{H}), 6.99(\mathrm{t}, J$ $=8.0 \mathrm{~Hz}, 1 \mathrm{H}), 6.98(\mathrm{dd}, J=8.3,1.0 \mathrm{~Hz}, 1 \mathrm{H}), 6.73(\mathrm{dd}, J=7.9,1.0 \mathrm{~Hz}, 1 \mathrm{H}), 6.66(\mathrm{dd}, J=8.0,1.0 \mathrm{~Hz}, 1 \mathrm{H}), 6.54(\mathrm{dd}$, $J=8.0,1.1 \mathrm{~Hz}, 1 \mathrm{H}), 4.59$ (bs, $1 \mathrm{H}), 3.73(\mathrm{~s}, 3 \mathrm{H}), 3.17$ (bs, $2 \mathrm{H}) ;{ }^{13} \mathrm{C} \mathrm{NMR}\left(100 \mathrm{MHz}, \mathrm{CDCl}_{3}\right) \delta 158.3,147.1,146.9$, 146.3, 145.1, 135.8, 129.2, 128.7, 127.83, 127.81, 127.6, 127.5, 126.9, 126.8, 124.1, 123.3, 123.1, 120.0, 114.2, 110.6, 82.9, 56.4; HRMS (CI+) calcd. for $\mathrm{C}_{26} \mathrm{H}_{22} \mathrm{NO}_{2} \mathrm{Cl}(\mathrm{M}+\mathrm{H}) 415.1339$, found 415.1359.

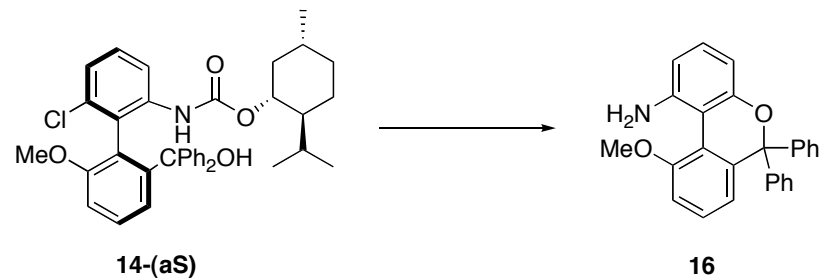

Dibenzopyran 16: To a pressure vessel was added the 14-(aS) (617 mg, $1.03 \mathrm{mmol}), \mathrm{KOH}(580 \mathrm{mg}, 10.3$ $\mathrm{mmol})$, and $n-\mathrm{BuOH}(2.06 \mathrm{~mL})$. The mixture was heated at $115^{\circ} \mathrm{C}$ for $22 \mathrm{~h}$ then quenched with $1 \mathrm{M} \mathrm{HCl}(30 \mathrm{~mL})$, diluted with EtOAc $(30 \mathrm{~mL})$ and washed with $\mathrm{H}_{2} \mathrm{O}(30 \mathrm{~mL})$ and sat. aq. $\mathrm{NaCl}(30 \mathrm{~mL})$. The dried extract $\left(\mathrm{MgSO}_{4}\right)$ was purified by silica gel chromatrography, eluting with $20 \%$ EtOAc / Hexanes. The material was recrystallized from hot EtOAc / Hexanes to yield 16 (359 mg, $0.948 \mathrm{mmol}, 92 \%)$ as a white crystalline solid. $\mathrm{Mp} 138-140^{\circ} \mathrm{C}$; IR 
(neat) $3439,3353,3057,1631,1562,1449 \mathrm{~cm}^{-1} ;{ }^{1} \mathrm{H}$ NMR (400 MHz, $\left.\mathrm{CDCl}_{3}\right) \delta 7.23-7.31(\mathrm{~m}, 10 \mathrm{H}), 7.25(\mathrm{t}, J=8.0$ $\mathrm{Hz}, 1 \mathrm{H}), 7.10(\mathrm{dd}, J=7.8,1.2 \mathrm{~Hz}, 1 \mathrm{H}), 7.00(\mathrm{t}, J=8.0 \mathrm{~Hz}, 1 \mathrm{H}), 6.61(\mathrm{dd}, J=8.0,1.0 \mathrm{~Hz}, 1 \mathrm{H}), 6.49$ (dd, $J=7.6,0.7$ $\mathrm{Hz}, 1 \mathrm{H}), 6.30(\mathrm{dd}, J=8.0,1.0 \mathrm{~Hz}, 1 \mathrm{H}), 4.45(\mathrm{bs}, 2 \mathrm{H}), 3.97(\mathrm{~s}, 3 \mathrm{H}) ;{ }^{13} \mathrm{C}$ NMR $\left(100 \mathrm{MHz}, \mathrm{CDCl}_{3}\right) \delta 155.2,154.5$, 145.2, 143.3, 143.2, 129.1, 129.0, 127.7, 127.65, 127.0, 121.5, 119.9, 112.5, 111.5, 110.5, 108.8, 87.4, 56.5; HRMS (CI+) calcd. for $\mathrm{C}_{26} \mathrm{H}_{21} \mathrm{NO}_{2}(\mathrm{M}+\mathrm{H}) 379.1572$, found 379.1576.

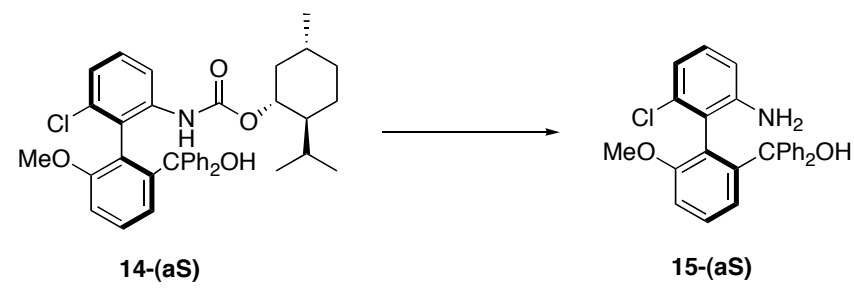

Anilino Alcohol 15-(aS): To a stirred solution of 14-(aS) (205 mg, $0.343 \mathrm{mmol})$, dihydro-2H-pyran (288 $\mathrm{mg}, 311 \mu \mathrm{L}, 3.43 \mathrm{mmol})$, and $\mathrm{CH}_{2} \mathrm{Cl}_{2}(1.14 \mathrm{~mL})$ was added $p$-toulenesulfonic acid $(6.5 \mathrm{mg}, 0.343 \mathrm{mmol})$ at r.t. After $2 \mathrm{~h}$, the mixture was quenched with sat. aq. $\mathrm{NaHCO}_{3}(15 \mathrm{~mL})$, diluted with EtOAc $(15 \mathrm{~mL})$ and washed with $\mathrm{H}_{2} \mathrm{O}(15 \mathrm{~mL})$, and sat. aq. $\mathrm{NaCl}(15 \mathrm{~mL})$. The dried extract $\left(\mathrm{MgSO}_{4}\right)$ was purified by column chromatography in $10 \%$ EtOAc / Hexanes to give the DHP-protected product $(212 \mathrm{mg}, 0.311 \mathrm{mmol})$ which was taken directly on to the next step. To a pressure vessel was added the DHP-protected compound (212 mg, $0.311 \mathrm{mmol}), \mathrm{KOH}$ (576 mg, $10.3 \mathrm{mmol}), n-\mathrm{BuOH}(1.40 \mathrm{~mL})$ and $\mathrm{EtOH}(2.1 \mathrm{~mL})$. The mixture was heated at $140^{\circ} \mathrm{C}$ for $24 \mathrm{~h}$. To this mixture was then added $1 \mathrm{M} \mathrm{HCl}(100 \mathrm{~mL})$ and $\mathrm{CH}_{2} \mathrm{Cl}_{2}(20 \mathrm{~mL})$ at r.t. After $3 \mathrm{~h}$, the mixture was extracted with $\mathrm{CH}_{2} \mathrm{Cl}_{2}(2$ x $100 \mathrm{~mL})$, washed with $\mathrm{H}_{2} \mathrm{O}(100 \mathrm{~mL})$ and sat. aq. $\mathrm{NaCl}(100 \mathrm{~mL})$. The dried extract $\left(\mathrm{MgSO}_{4}\right)$ was purified by silica gel chromatography, eluting with 20-50\% EtOAc / Hexanes to yield 15-(aS) (80.7 mg, $0.194 \mathrm{mmol}, 56 \%$ over 3 steps). Mp 110-111 ${ }^{\circ} \mathrm{C} ;[\alpha]_{\mathrm{D}}{ }^{23}=+77.6^{\circ}\left(\mathrm{c}=1.05, \mathrm{CHCl}_{3}\right.$ ); IR (neat) $3528,3333,2825,1623,1572 \mathrm{~cm}^{-1} ;{ }^{1} \mathrm{H}$ NMR $\left(300 \mathrm{MHz}, \mathrm{CDCl}_{3}\right) \delta 7.16-7.31(\mathrm{~m}, 11 \mathrm{H}), 6.99(\mathrm{t}, J=8.0 \mathrm{~Hz}, 1 \mathrm{H}), 6.98(\mathrm{dd}, J=8.3,1.0 \mathrm{~Hz}, 1 \mathrm{H}), 6.73(\mathrm{dd}, J=7.9$, $1.0 \mathrm{~Hz}, 1 \mathrm{H}), 6.66(\mathrm{dd}, J=8.0,1.0 \mathrm{~Hz}, 1 \mathrm{H}), 6.54(\mathrm{dd}, J=8.0,1.1 \mathrm{~Hz}, 1 \mathrm{H}), 4.59(\mathrm{bs}, 1 \mathrm{H}), 3.73(\mathrm{~s}, 3 \mathrm{H}), 3.17(\mathrm{bs}, 2 \mathrm{H})$; ${ }^{13} \mathrm{C} \mathrm{NMR}\left(100 \mathrm{MHz}, \mathrm{CDCl}_{3}\right) \delta 158.3,147.1,146.9,146.3,145.1,135.8,129.2,128.7,127.83,127.81,127.6,127.5$, $126.9,126.8,124.1,123.3,123.1,120.0,114.2,110.6,82.9,56.4$; HRMS (CI+) calcd. for $\mathrm{C}_{26} \mathrm{H}_{22} \mathrm{NO}_{2} \mathrm{Cl}(\mathrm{M}+\mathrm{H})$ 415.1339, found 415.1359 .
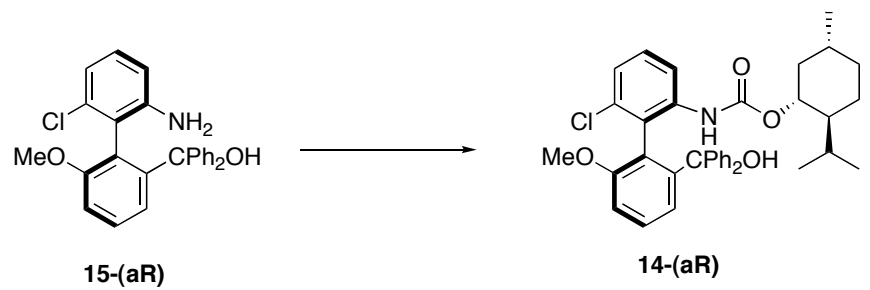

Carbamate 14-(aR): To a stirred solution of 15-(aR) (32.2 mg, $0.0776 \mathrm{mmol})$, DMAP (0.95 mg, 0.00776 $\mathrm{mmol})$ and pyridine $(0.39 \mathrm{~mL})$ was slowly added (-)-menthyl chloroformate $(84.8 \mathrm{mg}, 82.2 \mu \mathrm{L}, 0.388 \mathrm{mmol})$ at $0^{\circ} \mathrm{C}$. After $1 \mathrm{~h}$, the mixture was quenched with $\mathrm{NH}_{4} \mathrm{Cl}(15 \mathrm{~mL})$, diluted with $\mathrm{Et}_{2} \mathrm{O}(15 \mathrm{~mL})$ and washed with $\mathrm{NH}_{4} \mathrm{Cl}(15$ $\mathrm{mL}), \mathrm{H}_{2} \mathrm{O}(2 \times 15 \mathrm{~mL})$ and sat. aq. $\mathrm{NaCl}(15 \mathrm{~mL})$. The dried extract $\left(\mathrm{MgSO}_{4}\right)$ was purified by chromatography over silica gel, eluting with 50-75\% $\mathrm{CH}_{2} \mathrm{Cl}_{2} /$ Hexanes to give 14-(aR) as a single diastereomer (36.9 $\mathrm{mg}, 0.0618 \mathrm{mmol}$, $86 \%$ ). Mp 162-163 ${ }^{\circ} \mathrm{C} ;[\alpha]_{\mathrm{D}}{ }^{23}=-77.6^{\circ}\left(\mathrm{c}=2.08, \mathrm{CHCl}_{3}\right)$; IR (neat) $3569,3414,2954,1727,1575 \mathrm{~cm}^{-1} ;{ }^{1} \mathrm{H} \mathrm{NMR}$ $\left(400 \mathrm{MHz}, \mathrm{CDCl}_{3}\right) \delta 7.86(\mathrm{~d}, J=7.7 \mathrm{~Hz}, 1 \mathrm{H}), 7.35(\mathrm{t}, J=8.1 \mathrm{~Hz}, 1 \mathrm{H}), 7.18-7.33(\mathrm{~m}, 11 \mathrm{H}), 7.08(\mathrm{~d}, J=7.9 \mathrm{~Hz}, 1 \mathrm{H})$, $6.99(\mathrm{~d}, J=7.7 \mathrm{~Hz}, 1 \mathrm{H}), 6.66(\mathrm{~d}, J=7.9 \mathrm{~Hz}, 1 \mathrm{H}), 5.79(\mathrm{~s}, 1 \mathrm{H}), 4.54(\mathrm{td}, J=10.9,4.4 \mathrm{~Hz}, 1 \mathrm{H}), 3.67(\mathrm{~s}, 3 \mathrm{H}), 2.70(\mathrm{~s}$, $1 \mathrm{H}), 2.03(\mathrm{~d}, J=11.7 \mathrm{~Hz}, 1 \mathrm{H}), 1.65-1.72(\mathrm{~m}, 3 \mathrm{H}), 1.27(\mathrm{t}, J=12.0 \mathrm{~Hz}, 1 \mathrm{H}), 0.97(\mathrm{~d}, J=6.5 \mathrm{~Hz}, 3 \mathrm{H}), 0.85(\mathrm{~d}, J=$ $7.0 \mathrm{~Hz}, 3 \mathrm{H}), 0.81-1.10(\mathrm{~m}, 3 \mathrm{H}), 0.74(\mathrm{~d}, J=7.0 \mathrm{~Hz}, 3 \mathrm{H}) ;{ }^{13} \mathrm{C} \mathrm{NMR}\left(100 \mathrm{MHz}, \mathrm{CDCl}_{3}\right) \delta 158.0,153.1,146.8,146.1$, 145.9, 138.0, 134.8, 128.9, 128.1, 127.9, 127.8, 127.7, 127.6, 127.5, 127.4, 126.9, 123.9, 123.5, 122.6, 117.9, 110.4, 
83.5, 74.8, 56.2, 47.3, 41.5, 34.3, 21.4, 26.7, 24.1, 22.1, 20.5, 17.40; HRMS (EI+) calcd. for $\mathrm{C}_{37} \mathrm{H}_{40} \mathrm{NO}_{4} \mathrm{Cl}(\mathrm{M}+\mathrm{H})$ 597.2646, found 597.2642.
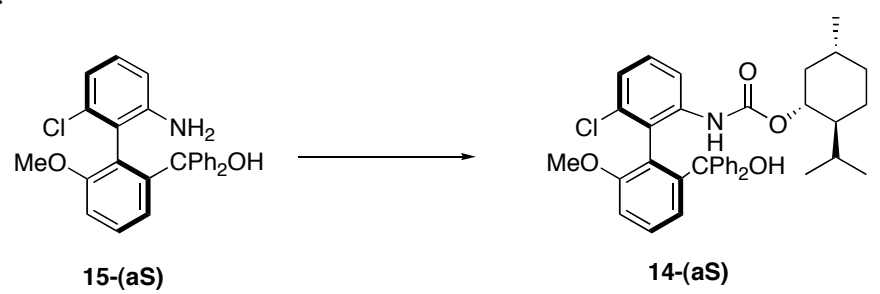

Carbamate 14-(aS): To a stirred solution of 15-(aS) (13.6 mg, $0.0328 \mathrm{mmol})$, DMAP $(0.40 \mathrm{mg}, 0.00328$ $\mathrm{mmol})$ and pyridine $(0.16 \mathrm{~mL})$ was slowly added $(-)$-menthyl chloroformate $(35.8 \mathrm{mg}, 34.8 \mu \mathrm{L}, 0.164 \mathrm{mmol})$ at $0^{\circ} \mathrm{C}$. After $1 \mathrm{~h}$, the mixture was quenched with $\mathrm{NH}_{4} \mathrm{Cl}(15 \mathrm{~mL})$, diluted with $\mathrm{Et}_{2} \mathrm{O}(15 \mathrm{~mL})$ and washed with $\mathrm{NH}_{4} \mathrm{Cl}(15$ $\mathrm{mL}), \mathrm{H}_{2} \mathrm{O}(2 \times 15 \mathrm{~mL})$ and sat. aq. $\mathrm{NaCl}(15 \mathrm{~mL})$. The dried extract $\left(\mathrm{MgSO}_{4}\right)$ was purified by chromatography over silica gel, eluting with 50-75\% $\mathrm{CH}_{2} \mathrm{Cl}_{2} /$ Hexanes to give 14-(aS) as a single diastereomer (16.3 $\mathrm{mg}, 0.0273 \mathrm{mmol}$, $83 \%) . \mathrm{Mp} 88-90^{\circ} \mathrm{C} ;[\alpha]_{\mathrm{D}}{ }^{23}=+18.8^{\circ}\left(\mathrm{c}=2.14, \mathrm{CHCl}_{3}\right) ; \mathrm{IR}$ (neat) $3556,3415,2955,1727,1575 \mathrm{~cm}^{-1} ;{ }^{1} \mathrm{H}$ NMR $(400$ $\left.\mathrm{MHz}, \mathrm{CDCl}_{3}\right) \delta 7.94(\mathrm{bs}, 1 \mathrm{H}), 7.36(\mathrm{t}, J=8.1 \mathrm{~Hz}, 1 \mathrm{H}), 7.19-7.34(\mathrm{~m}, 11 \mathrm{H}), 7.05(\mathrm{dd}, J=7.9,0.7 \mathrm{~Hz}, 1 \mathrm{H}), 7.01(\mathrm{~d}, J$ $=8.1 \mathrm{~Hz}, 1 \mathrm{H}), 6.68(\mathrm{~d}, J=8.0 \mathrm{~Hz}, 1 \mathrm{H}), 6.01(\mathrm{~s}, 1 \mathrm{H}), 4.61(\mathrm{td}, J=10.9,4.3 \mathrm{~Hz}, 1 \mathrm{H}), 3.70(\mathrm{~s}, 3 \mathrm{H}), 2.73(\mathrm{~s}, 1 \mathrm{H}), 1.97-$ $2.06(\mathrm{~m}, 3 \mathrm{H}), 1.73(\mathrm{~d}, J=11.7 \mathrm{~Hz}, 2 \mathrm{H}), 1.49-1.54(\mathrm{~m}, 1 \mathrm{H}), 1.33-1.41(\mathrm{~m}, 1 \mathrm{H}), 1.01(\mathrm{~d}, J=7.0 \mathrm{~Hz}, 3 \mathrm{H}), 0.94(\mathrm{~d}, J=$ $6.4 \mathrm{~Hz}, 3 \mathrm{H}), 0.88-1.16(\mathrm{~m}, 2 \mathrm{H}), 0.85(\mathrm{~d}, J=7.0 \mathrm{~Hz}, 3 \mathrm{H}) ;{ }^{13} \mathrm{C} \mathrm{NMR}\left(100 \mathrm{MHz}, \mathrm{CDCl}_{3}\right) \delta$ 158.2, 153.2, 146.8, 146.4, 145.7, 138.3, 134.8, 128.9, 128.8, 128.1, 127.9, 127.8, 127.7, 127.4, 127.3, 126.8, 123.9, 123.4, 122.8, 117.7, 110.6, 83.5, 75.1, 56.3, 47.1, 41.1, 34.3, 31.4, 25.9, 23.2, 22.1, 21.1, 16.3; HRMS (EI+) calcd. for $\mathrm{C}_{37} \mathrm{H}_{40} \mathrm{NO}_{4} \mathrm{Cl}(\mathrm{M}+\mathrm{H})$ 597.2646, found 597.2651.

1. A stock solution of LDA was prepared by addition of $n$-BuLi (5.93 mL, $14.3 \mathrm{mmol}, 2.41 \mathrm{M}$ in Hexanes) to a stirred solution of diisopropylamine $(1.44 \mathrm{~g}, 2.00 \mathrm{~mL}, 14.3 \mathrm{mmol})$ and THF $(6 \mathrm{~mL})$ at $-78^{\circ} \mathrm{C}$ for $1 \mathrm{~h}$.

2. To NaHMDS (4.93 mL, $4.93 \mathrm{mmol}, 1.0 \mathrm{M}$ in THF) at $-78^{\circ} \mathrm{C}$ was added a solution of 3dimethylaminocyclohexenone $(686 \mathrm{mg}, 4.93 \mathrm{mmol})$ in THF $(2.5 \mathrm{~mL})$ over $30 \mathrm{~min}$. TBSCl $(781 \mathrm{mg}, 5.18 \mathrm{mmol})$ in THF $(2.5 \mathrm{~mL})$ was added to the mixture. After $30 \mathrm{~min}$ at $-78^{\circ} \mathrm{C}$, the solution was allowed to warm to r.t. over $1 \mathrm{~h}$. Concentration in vacuo yielded the crude diene, which was used directly without purification. 